\title{
Exosomes in the gut
}

\author{
Lesley E. Smythies ${ }^{1 *}$ and John R. Smythies ${ }^{2}$ \\ Division of Gastroenterology and Hepatology, Department of Medicine, University of Alabama at Birmingham, Birmingham, AL, USA \\ ${ }^{2}$ Center for Brain and Cognition, University of California San Diego, San Diego, CA, USA \\ *Correspondence: lesmy@uab.edu \\ Edited by: \\ Eric Cox, Ghent University, Belgium \\ Reviewed by: \\ Charlotte Slayton Kaetzel, University of Kentucky, USA
}

Keywords: exosomes, mucosa, epithelial cells, dendritic cells, neurons, immunological synapses

\section{INTRODUCTION TO THE} GUT-MICROBIOTA PARADIGM

Recent studies have highlighted the importance of cross-talk between our immune systems and our gut microbiota, the complex community of over 100 trillion commensal microorganisms (bacteria, archaea, fungi, and protozoans) that resides in the human gastrointestinal tract and which numbers about 10 times the total cells in the human body (1). The gut microbiota contribute profoundly to the function and structure of the gastrointestinal mucosa, establishing a robust network that provides us with increased digestive capacity for essential nutrients and non-nutrient factors, such as vitamins. It also protects us from infection by pathogenic microbes (2). Dysbiosis, or unbalanced shifts in the composition of the microbiota, may contribute to inflammatory bowel disease and necrotizing enterocolitis in premature infants, and are also increasingly linked to rheumatoid arthritis, multiple sclerosis, diabetes, and asthma, as well as obesity (2).

The gastrointestinal tract, which is the largest mucosal surface in the body (with a surface area of about $300 \mathrm{~m}^{3}$ in adults), is lined by a single layer of polarized columnar epithelial cells firmly bound to one another by tight junctions and covered by a stratified mucus layer, that together provide a barrier containing the microbiota within the lumen. Cross-talk between the microbiota and immune cells of the mucosa [dendritic cells (DCs) and macrophages], communicated through this barrier, has regulated the evolution and development of our immune systems (3-6) and differentiated our ability to recognize and distinguish between beneficial and pathogenic microbes. Microbe recognition is achieved through epithelial cell and immune cell expression of germline-encoded pattern recognition receptors (PRRs) that bind discrete microbe-associated molecular patterns (MAMPS) expressed by both commensal and pathogenic microbes (7-9). PRR expression is tightly regulated on the apical and basolateral surfaces of the epithelial cells, such that binding of PRRs can activate a series of host defense reactions, including the directed release of soluble mediators, depending upon the nature of the antigen and the polarized epithelial surface communicating with the bacteria. Intestinal DCs orchestrate and direct mucosal adaptive immune responses, balancing immune tolerance to harmless antigens and effector responses against enteric pathogens (10). To facilitate these functions, populations of intestinal macrophages, and DCs, strategically located in the sub-epithelial lamina propria (11), sample luminal antigens provided by specialized epithelial cells (goblet cells) (12) or by inserting dendrites between epithelial cells into the lumen (1315), and phagocytose pathogenic microbes that encroach into the mucosa (11). DCs expressing the mucosal marker CD103, migrate to the MLNs, where they present acquired mucosal antigenic molecules to responsive naïve $\mathrm{T}$ cells $(16,17)$, inducing the expansion of tolerogenic or effector memory $\mathrm{T}$ cell populations expressing the gut homing markers $\alpha 4 \beta 7$ and CCR9 (18, 19), that support the T cell recruitment to the lamina propria.

\section{THE POSSIBLE ROLE OF EPITHELIAL CELL-DERIVED EXOSOMES IN THE REGULATION OF ADAPTIVE IMMUNE RESPONSES AGAINST THE MICROBIOTA}

In addition to the release of soluble mediators, epithelial cells also release a wide variety of proteins, lipids, mRNAs, and microRNAs contained within secreted nanovesicles, or exosomes, that are formed inside the secreting cells in endosomal compartments called multi-vesicular bodies (MVBs) (20, 21). Apical secretion of exosomes into the lumen may modulate the function of distant cells along the gastrointestinal tract, or regulate the homeostasis of gut microbiota, through delivery of antimicrobial products (22). Exosomes released basolaterally into the mucosa may also regulate local innate responses to invading bacteria through microbicidal activity (22). Moreover, epithelial cell-derived exosomes released into the mucosa may be taken up by mucosal DCs and transported to the MLNs, where their contents can effect the direction of mucosal adaptive immune responses, thereby directing the education of tolerogenic $\mathrm{CD} 4^{+} \mathrm{T}$ cell populations in conditions of homeostasis, as well as effector $\mathrm{CD} 4^{+} \mathrm{T}$ cells required to combat pathogenic microorganisms during microbial invasion or infection of the intestinal mucosa. Thus, intestinal epithelial cell-derived exosomes containing $\alpha v \beta 6$ integrin and food antigen are reported to induce TGF- $\beta^{+}$tolerogenic DCs and antigen-specific TGF- $\beta^{+}$T regulatory cells, whereas food antigens in the absence of exosomes, induce a Th2-skewed response (23). Conversely, exosomes contribute to protection against luminal infection with the protozoan parasite Cryptosporidium parvum, where activation of TLR4/IKK2 signaling and the promotion of the SNAP23-associated vesicular exocytotic process (22) induces the formation and release of exosomes into the lumen that contain epithelial cell-derived antimicrobial peptides, including cathelicidin-37 and beta-defensin 2. Inhibition of this TLR4 signaling decreases exosomal content, reducing the ability of the cell to target 
antimicrobial peptides against the infectious agent locally, and perhaps influencing host antigen presentation against the bacterium systemically (22) - important evidence that exosome contents are regulated by events occurring locally in the cells from which the exosomes derive. Taken together these data suggest that epithelial cell-derived exosomes play an important role, informing not only local innate immune responses, but also DC induction of adaptive immune responses, to luminal microbiota.

\section{THE FORMATION AND TRANSFER OF EXOSOMES FROM THE INTESTINAL LAMINA PROPRIA TO THE MESENTERIC LYMPH NODES}

Exosomes were first isolated from cultured cells, but are now known to be released from many cells including red blood cells, platelets, epithelial cells, lymphocytes, DCs, tumor cells (24-27). Exosome cargo is stringently regulated by the immune condition of the cells forming the vesicles, and their transfer, by direct cell-cell contact or across gap junctions or synapses, facilitates the exchange of molecular messages, even over considerable distances. In the formation of exosomes, all types of cell so far examined bud off from their plasma membranes small lipoprotein vesicles (around $80 \mathrm{~mm}$ ) that contain a wide variety of molecules including proteins, various types of RNA including mRNAs and microRNAs, DNA, lipid, and saccharides (28). Exosomes are constructed inside MVBs within the donor cell by invagination of its membrane. A complex mechanism then uploads a number of specific molecules into the exosome as its cargo. The MVB is then trafficked to the plasma membrane with which it fuses to release the contained exosomes into "extracellular space."

Importantly, the exosomal lipoprotein vesicular coats protect the exosome cargo from degradation (29), even from highly destructive elements such as catabolic enzymes found within phagolysosomes, thus it is likely that exosomes remain undamaged when taken up by DCs in the mucosa. Within the lymph node, transfer of cargo from the DC to the T cell is thought to involve the immune synapse (IS), which is intimately involved in antigen presentation between DCs and T cells. Exosomes are taken up within the IS by calveoli- or clathrin-dependent mechanisms $(30,31)$, and transported to specific loci in the receiving cell, including the perinuclear zone, where the vesicle opens and the cargo is released. A model for the transfer of exosomes across the IS may be provided by the manner by which an exosome probably crosses the synapse between neurons. The traditional picture of a synapse was that the axon terminal and the postsynaptic spine are separated by "extracellular space" filed with cytoplasm. The exosome was pictured as crossing this fluid cytoplasm. However, electron microscopy shows that such "space" is vanishingly thin. Instead, the "space" is mainly filled with astrocyte cuffs tightly packed around the central part of the synapse plus a network of nanotubes and fibers crossing the central part (32-35). This central part is specialized for the transmission of neurotransmitter molecules, and the outer ring for the transmission of exosomes (36). Astrocytes both receive (37) and bud off $(38,39)$ exosomes, so it is likely that exosomes cross the synapse via the astrocyte cuff and nanotubules.

Much of the load carried by exosomes consists of epigenetic material (protein transcription factors, a wide variety of RNAs, and lengths of DNA). Epigenetic material consists of four main categories: (a) molecules that act directly on DNA by promoting co-valent binding (e.g., DNA methylases and demethylases) or non-covalent binding (e.g., protein transcription factors); (b) agents that module the accessibility of DNA by promoting co-valent binding to histones (e.g., histone methylases and acetylases); (c) mRNAs that induce de novo protein synthesis in the target cell; and (d) micro RNAs that bind to mRNAs and modulate their activity (28). Exosomes from different types of cell carry different patterns of these transcription factors in their loads. In many cells, such as neurons, exosome formation is closely modulated by the degree of activity of that cell. For example, activation of glutamate receptors leads to a marked increase in exosome production mediated by calcium inflow. The exact composition of exosome loads is also exquisitely sensitive to the functional condition of the donor cell. For example, when a normal cell becomes cancerous, the ingredients of the load that its exosomes carry changes dramatically (28). Furthermore, the surfaces of different types of exosomes carry different patterns of glycosylation that can act as identifying signals, so that the exosome will bind to complementary patterns of glycosylation on the correct target cell (40). Other possible identification molecules that would allow an exosome to bind to its proper target are the heparin sulfate proteoglycans (HSPGs). Exosomes have been shown to enter cells via HSPG-mediated endocytosis. Heparanse enzyme activity is required for robust enhancement of exosome secretion (41-44). Exosomes from cancer cells depend on cell-surface HSPGs for their internalization and functional activity (30).

\section{CONCLUSION}

This scenario offers an exciting new paradigm. Firstly, exosomes released from the apical or basolateral surface of gastrointestinal epithelium may contribute to antimicrobial defenses in the gut lumen. Secondly, and more interestingly, exosomes may be transported to the MLN where they modulate, by the epigenetic mechanisms listed above, host adaptive responses to luminal antigens. We are thus suggesting that there are two channels of communication between intestinal epithelial cells and target $\mathrm{T}$ cells in lymph nodes. The first transmits information ("software") reflecting the contents of the gut, obtained and transmitted by DCs in the manner described earlier. The second channel transmits epigenetic instructions, in particular specific miRNAs, via exosomes to the $\mathrm{T}$ cell, so that it can develop the optimum molecular mechanisms or reactions ("hardware") to process the incoming "software." A similar system is found in the nervous system (28): information about the environment is transmitted by spike codes in axons ("software") and instructions on how to best process this software is transmitted by epigenetic molecules via contained within exosomes. Together this results in changes in the basic functions of the receiving neurons by altering the synthesis of key proteins that play an essential role in these processes.

\section{ACKNOWLEDGMENTS}

Funding support is provided by National Institutes of Health grant AI-83539, The 
Broad Medical Research Program of The Broad Foundation, and The Crohn's and Colitis Foundation of America. We are grateful to Sasha Vlassov for the benefit of helpful information.

\section{REFERENCES}

1. Ley RE, Peterson DA, Gordon JI. Ecological and evolutionary forces shaping microbial diversity in the human intestine. Cell (2006) 124:837-48. doi:10.1016/j.cell.2006.02.017

2. Maynard CL, Elson CO, Hatton RD, Weaver CT. Reciprocal interactions of the intestinal microbiota and immune system. Nature (2012) 489:231. doi:10.1038/nature 11551

3. Falk PG, Hooper LV, Midtvedt T, Gordon JI. Creating and maintaining the gastrointestinal ecosystem: what we know and need to know from gnotobiology. Microbiol Mol Biol Rev (1998) 62:1157.

4. Macpherson AJ, Harris NL. Interactions between commensal intestinal bacteria and the immune system. Nat Rev Immunol (2004) 4:478. doi:10. 1038/nri1373

5. Duan J, Chung H, Troy E, Kasper DL. Microbial colonization drives expansion of IL-1 receptor 1expressing and IL-17-producing gamma/delta T cells. Cell Host Microbe (2010) 7:140. doi:10.1016/ j.chom.2010.01.005

6. Niess JH, Leithäuser F, Adler G, Reimann J. Commensal gut flora drives the expansion of proinflammatory CD4 T cells in the colonic lamina propria under normal and inflammatory conditions. J Immunol (2008) 180:559.

7. Lundin A, Bok CM, Aronsson L, Björkholm B, Gustafsson JA, Pott S, et al. Gut flora, Toll-like receptors and nuclear receptors: a tripartite communication that tunes innate immunity in large intestine. Cell Microbiol (2008) 10:1093. doi:10. 1111/j.1462-5822.2007.01108.x

8. Smythies LE, Shen R, Bimczok D, Novak L, Clements RH, Eckhoff DE, et al. Inflammation anergy in human intestinal macrophages is due to Smad-induced IkappaBalpha expression and NF-kappaB inactivation. J Biol Chem (2010) 285:19593-604. doi:10.1074/jbc.M109.069955

9. Smith PD, Smythies LE, Shen R, Greenwell-Wild T, Gliozzi M, Wahl SM. Intestinal macrophages and response to microbial encroachment. Mucosal Immunol (2011) 1:31-42. doi:10.1038/mi.2010.66

10. Farache J, Koren I, Milo I, Gurevich I, Kim KW, Zigmond E, et al. Luminal bacteria recruit $\mathrm{CD}_{103}{ }^{+}$dendritic cells into the intestinal epithelium to sample bacterial antigens for presentation. Immunity (2013) 38:581-95. doi:10.1016/j. immuni.2013.01.009

11. Smythies LE, Sellers M, Clements RH, MostellerBarnum M, Meng G, Benjamin WH, et al. Human intestinal macrophages display profound inflammatory anergy despite avid phagocytic and bacteriocidal activity. J Clin Invest (2005) 115:66-75. doi:10.1172/JCI200519229

12. McDole JR, Wheeler LW, McDonald KG, Wang B, Konjufca V, Knoop KA, et al. Goblet cells deliver luminal antigen to $\mathrm{CD}_{103}{ }^{+}$dendritic cells in the small intestine. Nature (2012) 483:345-9. doi:10. 1038/nature10863
13. Niess JH, Brand S, Gu X, Landsman L, Jung S, McCormick BA, et al. CX3CR1-mediated dendritic cell access to the intestinal lumen and bacterial clearance. Science (2005) 307:254-8.

14. Chieppa M, Rescigno M, Huang AY, Germain RN. Dynamic imaging of dendritic cell extension into the small bowel lumen in response to epithelial cell TLR engagement. J. Exp Med (2006) 203:2841-52. doi:10.1084/jem.20061884

15. Farache J, Zigmond E, Shakhar G, Jung S. Contributions of dendritic cells and macrophages to intestinal homeostasis and immune defense. Immunol Cell Biol (2013) 91:232-9. doi:10.1038/ icb.2012.79

16. Bogunovic M, Ginhoux F, Helft J, Shang L, Hashimoto D, Greter M, et al. Origin of the lamina propria dendritic cell network. Immunity (2009) 31:513-25. doi:10.1016/j.immuni.2009.08.010

17. Schulz O, Jaensson E, Persson EK, Liu X, Worbs $\mathrm{T}$, Agace WW, et al. Intestinal CD103p, but not CX3CR1p, antigen sampling cells migrate in lymph and serve classical dendritic cell functions. J Exp Med (2009) 206:3101-14. doi:10.1084/jem. 20091925

18. Johansson-Lindbom B, Svensson M, Pabst O, Palmqvist C, Marquez G, Fo“rster R, et al. Functional specialization of gut CD103 dendritic cells in the regulation of tissue-selective $\mathrm{T}$ cell homing. J Exp Med (2005) 202:1063-73. doi:10.1084/jem. 20051100

19. Jaensson E, Uronen-Hansson H, Pabst O, Eksteen B, Tian J, Coombes JL, et al. Small intestinal CD103p dendritic cells display unique functional properties that are conserved between mice and humans. J Exp Med (2008) 205:2139-49. doi:10. 1084/jem.20080414

20. Mallegol J, Van Niel G, Lebreton C, Lepelletier Y, Candalh C, Dugave C, et al. T84-intestinal epithelial exosomes bear MHC class II/peptide complexes potentiating antigen presentation by dendritic cells. J Gastro. (2007) 132:1866. doi:10.1053/ j.gastro.2007.02.043

21. van Niel G, Raposo G, Candalh C, Boussac M, Hershberg R, Cerf-Bensussan $\mathrm{N}$, et al. Intestinal epithelial cells secrete exosome-like vesicles. Gastroenterology (2001) 121:337-49.

22. Hu G, Gong AY, Roth AL, Huang BQ, Ward HD, Zhu G, et al. Release of luminal exosomes contributes to TLR4-mediated epithelial antimicrobial defense. Plos Pathog (2013) 9. doi:10.1371/journal. ppat. 1003261

23. Chen X, Song CH, Feng BS, Li TL, Li P, Zheng PY, et al. Intestinal epithelial cell-derived integrin $\alpha \beta 6$ plays an important role in the induction of regulatory $\mathrm{T}$ cells and inhibits an antigen-specific Th2 response. J Leuko Biol (2006) 90:751-9. doi: 10.1189/jlb.1210696

24. Théry C, Zitvogel L, Amigorena S. Exosomes: composition, biogenesis and function. Nat Rev Immunol (2002) 2:569-79.

25. Andre F, Schartz NE, Movassagh M, Flament C, Pautier P, Morice P, et al. Malignant effusions and immunogenic tumour-derived exosomes. Lancet (2002) 360:295-305. doi:10.1016/S0140-6736(02) 09552-1

26. Smalheiser NR. Exosomal transfer of proteins and RNAs at synapses in the nervous system. Biol Direct (2007) 2:35. doi:10.1186/1745-6150-2-35
27. Hendrix A, Westbroek W, Bracke M, Wever OD. An ex(o)citing machinery for invasive tumor growth. Cancer Res (2010) 70:9533-7. doi:10.1158/00085472.CAN-10-3248

28. Smythies J, Edelstein L. Transsynaptic modality codes in the brain: possible involvement of synchronized spike timing, microRNAs, exosomes and epigenetic processes. Front Intregr Neurosci (2013) 2012(6):126. doi:10.3389/fnint.2012.00126

29. Keller S, Ridinger J, Rupp AK, Janssen JW, Altevogt P. Body fluid derived exosomes as a novel template for clinical diagnostics. J Transl Med (2011) 9:86. doi:10.1186/1479-5876-9-86

30. Nanbo A, Kawanishi E, Yoshida R, Yoshiyama H. Exosomes derived from Epstein-Barr virusinfected cells are internalized via caveoladependent endocytosis and promote phenotypic modulation in target cells. J Virol (2013) 87:10334-47. doi:10.1128/JVI.01310- 13

31. Frühbeis C, Fröhlich D, Kuo WP, Amphornrat J, Thilemann S, Saab AS, et al. Neurotransmittertriggered transfer of exosomes mediates oligodendrocyte-neuron communication. PLoS Biol (2013) 11:e1001604. doi:10.1371/journal.pbio.1001604

32. Agnati LF, Guidolin D, Guescini M, Battistin L, Stocchi V, De Caro R, et al. Aspects on the integrative actions of the brain from neural networks to "brain-body medicine." J Recept Signal Transduct Res (2012) 32:163-80. doi:10.3109/10799893. 2012.687748

33. Marzo L, Gousset K, Zurzolo C. Multifaceted roles of tunneling nanotubes in intercellular communication. Front Physiol (2012) 3:72. doi:10.3389/ fphys.2012.00072

34. Fuxe K, Borroto-Escuela DO, Romero-Fernandez W, Zhang WB, Agnati LF. Volume transmission and its different forms in the central nervous system. Chin J Integr Med (2013) 19:323-9. doi:10.1007/ s11655-013-1455-1

35. Kinney JP, Spacek J, Bartol TM, Chandrajit LB, Harris KM, Sejnowski TJ. Extracellular sheets and tunnels modulate glutamate diffusion in hippocampal neuropil. J Comp Neurol (2013) 521:448-64. doi:10.1002/cne.23181

36. Koles K, Budnik V. Exosomes go with the Wnt. Cell $\log$ (2012) 2:1-5.

37. Morel L, Regan M, Higashimori H, Ng SK, Esau C, Vidensky S, et al. Neuronal exosomal miRNA-dependent translational regulation of astroglial glutamate transporter GLT1. J Biol Chem (2013) 288:7105-16. doi:10.1074/jbc.M112. 410944

38. Basso M, Pozzi S, Tortarolo M, Fiordaliso F, Bisighini C, Pasetto L, et al. Mutant copper-zinc superoxide dismutase (SOD1) induces protein secretion pathway alterations and exosome release in astrocytes: implications for disease spreading and motor neuron pathology in amyotrophic lateral sclerosis. J Biol Chem (2013) 288:15699-711. doi:10.1074/ jbc.M112.425066

39. Wang G, Dinkins M, He Q, Zhu G, Poirier C, Campbell A, et al. Astrocytes secrete exosomes enriched with proapoptotic ceramide and prostate apoptosis response 4 (PAR-4): potential mechanism of apoptosis induction in Alzheimer disease (AD). J Biol Chem (2012) 287:21384-95. doi:10.1074/jbc.M112.340513 
40. Batista BS, Eng WS, Pilobello KT, HendricksMuñoz KD, Mahal LK. Identification of a conserved glycan signature for microvesicles. J Proteome Res (2011) 10:4624-33. doi:10.1021/ pr200434y

41. Thompson CA, Purushothaman A, Ramani VC, Vlodavsky I, Sanderson RD. Heparanase regulates secretion, composition, and function of tumor cell-derived exosomes. J Biol Chem (2013) 288:10093-9. doi:10.1074/jbc.C112.444562

42. Christianson HC, Belting M. Heparan sulfate proteoglycan as a cell-surface endocytosis receptor. Matrix Biol (2013). S945-53. doi:10.1016/j. matbio.2013.10.004
43. Christianson HC, Svensson KJ, van Kuppevelt TH, Li JP, Belting M. Cancer cell exosomes depend on cell-surface heparan sulfate proteoglycans for their internalization and functional activity. Proc Natl Acad Sci U S A. (2013) 110(43):17380-5. doi:10.1073/pnas.1304266110

44. Guescini M, Genedani S, Stocchi V, Agnati LF. Astrocytes and glioblastoma cells release exosomes carrying mtDNA. J Neural Transm (2010) 117:1-4. doi:10.1007/s00702-009-0288-8

Received: 24 December 2013; accepted: 28 February 2014; published online: 17 March 2014.
Citation: Smythies LE and Smythies JR (2014) Exosomes in the gut. Front. Immunol. 5:104. doi 10.3389/fimmu.2014.00104

This article was submitted to Mucosal Immunity, a section of the journal Frontiers in Immunology.

Copyright (C) 2014 Smythies and Smythies. This is an open-access article distributed under the terms of the Creative Commons Attribution License (CC BY). The use, distribution or reproduction in other forums is permitted, provided the original author(s) or licensor are credited and that the original publication in this journal is cited, in accordance with accepted academic practice. No use, distribution or reproduction is permitted which does not comply with these terms. 